\title{
BMJ Global Health Workforce capacity for the care of patients with kidney failure across world countries and regions
}

\author{
Parnian Riaz, ${ }^{1}$ Fergus Caskey, ${ }^{2}$ Mark Mclsaac, ${ }^{1}$ Razeen Davids, ${ }^{3}$ Htay Htay, ${ }^{4}$ \\ Vivekanand Jha, ${ }^{5}$ Kailash Jindal, ${ }^{6}$ Min Jun, ${ }^{7}$ Maryam Khan, ${ }^{8}$ Adera Levin, ${ }^{9}$ \\ Meaghan Lunney, ${ }^{10}$ Ikechi Okpechi (D) , ${ }^{1,11}$ Roberto Pecoits-Filho, ${ }^{12}$ \\ Mohamed A Osman, ${ }^{6}$ Tushar Vachharajani, ${ }^{13}$ Feng Ye, ${ }^{1}$ David Harris, ${ }^{14}$ \\ Marcello Tonelli, ${ }^{15}$ David Johnson, ${ }^{16}$ Aminu Bello ${ }^{1}$
}

To cite: Riaz P, Caskey F, Mclsaac M, et al. Workforce capacity for the care of patients with kidney failure across world countries and regions. BMJ Global Health 2021;6:e004014. doi:10.1136/ bmjgh-2020-004014

Handling editor Seye Abimbola

- Additional material is published online only. To view please visit the journal online (http://dx.doi.org/10.1136/ bmjgh-2020-004014).

Received 21 September 2020 Revised 19 December 2020 Accepted 23 December 2020

Check for updates

(c) Author(s) (or their employer(s)) 2021. Re-use permitted under CC BY-NC. No commercial re-use. See rights and permissions. Published by BMJ.

For numbered affiliations see end of article.

Correspondence to

Dr Aminu Bello;

aminu1@ualberta.ca

\section{ABSTRACT}

Introduction An effective workforce is essential for optimal care of all forms of chronic diseases. The objective of this study was to assess workforce capacity for kidney failure (KF) care across world countries and regions. Methods Data were collected from published online sources and a survey was administered online to key stakeholders. All country-level data were analysed by International Society of Nephrology region and World Bank income classification.

Results The general healthcare workforce varies by income level: high-income countries have more healthcare workers per 10000 population (physicians: 30.3 ; nursing personnel: 79.2; pharmacists: 7.2; surgeons: 3.5 ) than low-income countries (physicians: 0.9 ; nursing personnel: 5.0; pharmacists: 0.1 ; surgeons: 0.03 ). A total of 160 countries responded to survey questions pertaining to the workforce for the management of patients with KF. The physicians primarily responsible for providing care to patients with KF are nephrologists in $92 \%$ of countries. Global nephrologist density is 10.0 per million population (pmp) and nephrology trainee density is $1.4 \mathrm{pmp}$. Highincome countries reported the highest densities of nephrologists and nephrology trainees (23.2 pmp and 3.8 pmp, respectively), whereas low-income countries reported the lowest densities ( $0.2 \mathrm{pmp}$ and $0.1 \mathrm{pmp}$, respectively). Low-income countries were most likely to report shortages of all types of healthcare providers, including nephrologists, surgeons, radiologists and nurses.

Conclusions Results from this global survey demonstrate critical shortages in workforce capacity to care for patients with KF across world countries and regions. National and international policies will be required to build a workforce capacity that can effectively address the growing burden of KF and deliver optimal care.

\section{INTRODUCTION}

The global burden of chronic kidney disease (CKD) continues to rise, with a current prevalence estimated at $13.4 \% .^{1-3}$ Patients with kidney disease are notably complex, with recent studies showing that nephrologists

\section{Key questions}

What is already known?

- Many countries in developing economies, especially in Latin America, Africa and parts of Asia, have a scarcity of all cadres of healthcare workers.

- There is a scarcity of nephrologists in many countries in the world; however, the extent of this scarcity has not been previously fully quantified.

What are the new findings?

- Our data show a varying scarcity of workforce in nephrology across all sectors (physicians, surgeons nurses, technicians) in different parts of the world.

- There is a very low nephrology trainee density in mainly developing world regions which further impacts on density of nephrologists.

\section{What do the new findings imply?}

- A demonstration of critical shortages in workforce capacity to care for patients with kidney failure across world countries and regions.

- The need for national and international policies to build a workforce capacity that can effectively address the growing burden of kidney failure and deliver optimal care.

rank highest compared with all other general and medical subspecialists with regard to patient complexity. ${ }^{4}$ The presence of CKD indicates a higher risk of adverse events for patients with diabetes, hypertension and cardiovascular disease. ${ }^{256}$ Furthermore, CKD is associated with increasing healthcare costs. ${ }^{5}$

The delivery of comprehensive kidney disease care, including risk factor modification, kidney replacement therapy (dialysis and kidney transplantation), delivery and transplant services, requires a large workforce with adequate geographical coverage to meet the growing healthcare needs of patients with CKD. ${ }^{2578}$ However, recent surveys from the 
first iteration of the International Society of Nephrology Global Kidney Health Atlas (ISN-GKHA) revealed a global shortage of nephrologists and other healthcare providers essential for kidney disease care, with a much greater disparity reported in lower income countries. ${ }^{9}$ The nephrology workforce is predicted to further decrease in size and capacity over the next decade, which will further exacerbate current demand for kidney disease care. ${ }^{10}$

The second iteration of the ISN-GKHA was a multinational, cross-sectional survey to assess international variability in the capacity for kidney failure care. One aim of the survey was to assess the current global workforce capacity for kidney failure care and identify areas with healthcare provider shortages. This is the first study to provide data regarding the availability of not only nephrologists and nephrology trainees, but also other healthcare professionals involved in kidney failure care worldwide.

\section{METHODS}

The ISN-GKHA is a project targeted at monitoring and evaluating global capacity for kidney care that combines desk research with an international survey of key stakeholders. The full methodology for the second iteration of the ISN-GKHA has been published elsewhere, ${ }^{11-13}$ as have details about the development and validation of the survey. ${ }^{1314}$ Two iterations of the survey were conducted in 2016 and 2018. ${ }^{11}{ }^{14}$ Here, we report responses to items from the second survey conducted in 2018 related to workforce capacity for kidney failure care.

\section{Desk research}

Desk research efforts involved a broad literature review in April 2020 of national health systems associated with health workforce to determine the density of physicians, surgeons, nursing personnel and pharmacists in individual countries. Data sources included The World Factbook from the Central Intelligence Agency $(\text { CIA })^{15}$ and the Global Health Observatory Data Repository from the WHO. ${ }^{16-18}$

\section{Survey data}

The ISN-GKHA questionnaire was designed to assess national and regional profiles for readiness, capacity and responsiveness to kidney failure, including questions about the availability of nephrologists, nephrology trainees and other healthcare providers essential for kidney failure care delivery. A non-probability, purposive sampling approach was used to identify survey respondents. National and regional nephrology leaders affiliated with the ISN identified key stakeholders, including representatives of national nephrology societies, policymakers, patient organisations, foundations and other advocacy groups. Key stakeholders were sent invitations to participate in the survey through a link to the survey's online portal, an electronic questionnaire via REDCap Cloud (www.redcapcloud.com). Three key opinion leaders from each country were invited to complete the survey: a nephrology society leader, a leader of a consumer representative organisation and a policymaker.

The survey was conducted from July to September 2018; during this period, intensive follow-up was conducted by email and phone with ISN regional and national leaders to ensure complete and timely responses. Regional and national project leaders were identified through international contacts, collaborators, ISN leaders and the ISN's 10 Regional Boards (Africa, Eastern and Central Europe, Latin America, the Middle East, North America and the Caribbean, North and East Asia, Oceania and Southeast Asia, the Newly Independent States (NIS) and Russia, South Asia, and Western Europe). The ISN regions are based on geographical proximity of countries that enable the ISN to effectively engage in advocacy and implement training and educational programmes in those areas. For instance, although Mexico is part of North America, it is part of the ISN's Latin American region (https:// www.theisn.org/about-isn/regions). Each project leader was responsible for: (a) organising and following up on responses from each region and country; (b) serving as a liaison between the steering committee, the ISN and regional/national stakeholders; (c) providing access to additional data sources and contacts for surveys; (d) identifying or serving as an opinion leader on the project for the region/country; and (e) identifying or serving as a resource person to vet and review regional/national data.

\section{Data handling and statistical analysis}

For the survey data, after responses to the French and Spanish versions of the survey were translated into English by certified translators, data were extracted from all individual questionnaires and cleaned using Microsoft Excel. Responses were merged into a single file to create the global database. ISN regional leaders were consulted to ensure that the collected data were consistent with their understandings and were of high quality. Any major inconsistencies in responses at the country level were addressed with the stakeholders involved with the survey and clarified by ISN regional leaders when necessary. Using country as the unit of analysis, we imported the data into Stata V.15 software (Stata Corporation, 2017) and analysed it using a well-validated framework developed by the WHO: Assessing National Capacity for the Prevention and Control of Non-Communicable Diseases. We validated our results by triangulating the findings with academic research and grey literature, including government reports. The responses for survey items were summarised using descriptive statistics to report absolute counts and percentages. The density of each category of healthcare provider, including physicians, nursing personnel, surgeons, pharmacists, nephrologists and nephrology trainees, was calculated as the total number of healthcare provider divided by the country's total population. Country population was obtained from the World Factbook of the CIA. ${ }^{15}$ Data were reported using 

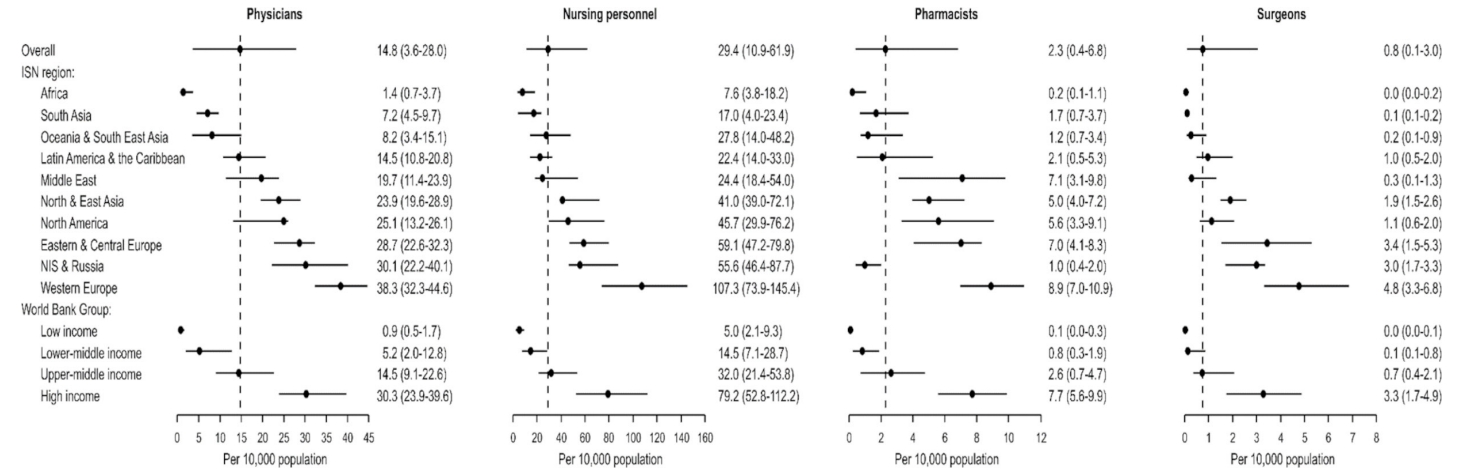

Figure 1 Density of healthcare providers (per 10000 population) (regional data for physicians are presented in ascending order (median and IQR)). Density of physicians, nursing personnel, pharmacists and surgeons, calculated by taking the total number of physicians, nursing personnel, pharmacists and surgeons reported in each country, respectively, and dividing it by each country's population, grouped by ISN region and World Bank income group. Data from: The World Factbook from the Central Intelligence Agency ${ }^{15}$ and the Global Health Observatory Data Repository from the WHO. ${ }^{16-18}$ ISN, International Society of Nephrology; NIS, Newly Independent States.

median (IQR) and results were stratified by ISN region and World Bank income group.

\section{Patient and public involvement}

Patients were not involved in our study. Members of the global nephrology community participated in this survey.

\section{RESULTS}

\section{Availability (regional densities) of healthcare providers}

Data from 196 countries were evaluated to assess the regional densities of physicians, nursing personnel, pharmacists and surgeons. All the data in this section are presented as number per 10000 population. The global median density of physicians was 14.8 (IQR 3.6-27.9), with the highest densities in Western Europe (38.3), the NIS and Russia (30.1), Eastern and Central Europe (28.7), North America (25.1), and North and East Asia (23.9). Densities of physicians in the Middle East (19.7) and Latin America and the Caribbean (14.5) were close to the global median. The lowest densities of physicians were in Oceania and Southeast Asia (8.2), South Asia (7.2) and Africa (1.4). A direct relationship existed between physician density and World Bank income group (high income: 30.3; upper-middle income: 14.5; lower-middle income: 5.2; low-income: 0.9) (figure 1). Nursing personnel had the highest median global density compared with other healthcare professionals (29.4, IQR 10.9-60.9). However, there was significant variability in the density of nursing personnel across ISN regions, with the highest density in Western Europe (107.9) and the lowest density in Africa (6.7) (figure 1). The global median density of pharmacists was 2.3 (IQR 0.4-6.8). High-income countries had the highest density of pharmacists (7.2), followed by upper-middle-income countries (2.8), lower-middle-income countries (0.8) and low-income countries (0.1) (figure 1). Among all healthcare professionals, the global density of surgeons was the lowest, at 0.8 (IQR 0.1-3.0) (figure 1).
Current density of nephrologists across countries and regions Representatives from 160 countries (88\%) representing $98 \%$ of the world's population responded to survey questions about nephrologist density (online supplemental table S1). Overall, the global median number of nephrologists per million population (pmp) was 9.9 (IQR 1.2-22.7). The data revealed significant regional variability in the density of nephrologists (table 1 ). The regions with the highest nephrologist densities were Western Europe (24.4 pmp) and Eastern and Central Europe $(25.6 \mathrm{pmp})$, followed by North and East Asia (19.5 pmp), North America (18.1 pmp), and the NIS and Russia (14.4 pmp). Nephrologist density was close to the global median in two regions (Latin America and the Caribbean: 9.8 pmp; the Middle East: $8.1 \mathrm{pmp}$ ), and below the global median in three regions (Oceania and Southeast Asia: 5.7 pmp; South Asia: 1.2 pmp; Africa: 0.6 pmp). Nephrologist density was directly associated with World Bank income group and varied widely, ranging from $23.2 \mathrm{pmp}$ in high-income countries to $10.8 \mathrm{pmp}$ in upper-middle, 1.6 in lower-middle and $0.2 \mathrm{pmp}$ in lowincome countries (table 1 ).

\section{Current density of nephrology trainees across countries and regions}

Representatives from 144 countries (79\%) responded to survey questions regarding nephrology trainee density. The global median density for nephrology trainees was $1.4 \mathrm{pmp}$ (IQR 0.4-3.7). Relative to the density of nephrologists, the data showed less regional variability in the density of nephrology trainees, which ranges from 5.7 pmp in Western Europe to $0.0 \mathrm{pmp}$ in North America, where the absolute number of trainees was 637 (table 1). Of the eight countries in North America, five reported that they currently had no nephrology trainees. Three countries, Canada, the USA, and St. Kitts and Nevis, reported having nephrology trainees. The density of nephrology trainees was lower than the global median in 
Table 1 Global distribution of the nephrology workforce, per million population (pmp)

\begin{tabular}{|c|c|c|c|c|c|c|}
\hline \multirow[b]{2}{*}{ Category } & \multicolumn{3}{|c|}{ Nephrologist density } & \multicolumn{3}{|c|}{ Nephrology trainee density } \\
\hline & $\begin{array}{l}\text { Total no of } \\
\text { respondent } \\
\text { countries }\end{array}$ & Median & IQR & $\begin{array}{l}\text { Total no of } \\
\text { respondent } \\
\text { countries }\end{array}$ & Median & IQR \\
\hline Overall & 152 & 9.95 & $(1.23-22.72)$ & 144 & 1.42 & $(0.35-3.70)$ \\
\hline \multicolumn{7}{|l|}{ ISN region } \\
\hline Africa & 39 & 0.62 & $(0.24-1.56)$ & 35 & 0.36 & $(0.06-0.92)$ \\
\hline Eastern and Central Europe & 19 & 25.63 & (15.54-36.73) & 19 & 3.26 & $(1.56-4.42)$ \\
\hline Latin America and the Caribbean & 18 & 9.76 & (8.73-19.73) & 18 & 1.37 & $(0.84-3.18)$ \\
\hline Middle East & 11 & 8.08 & $(4.97-15.87)$ & 11 & 1.82 & $(0.72-2.86)$ \\
\hline NIS and Russia & 8 & 14.41 & $(6.62-22.33)$ & 7 & 1.60 & $(0.46-3.25)$ \\
\hline North America & 9 & 18.13 & $(15.33-29.46)$ & 8 & $0.00^{\star}$ & $(0.00-1.74)$ \\
\hline North and East Asia & 7 & 19.45 & $(9.67-54.60)$ & 7 & 3.22 & $(1.94-5.94)$ \\
\hline Oceania and Southeast Asia & 14 & 5.66 & $(1.08-16.59)$ & 15 & 1.08 & $(0.30-4.51)$ \\
\hline South Asia & 7 & 1.15 & $(0.63-1.39)$ & 6 & 0.29 & $(0.15-0.62)$ \\
\hline Western Europe & 20 & 24.36 & $(18.07-29.91)$ & 18 & 5.80 & (3.73-8.03) \\
\hline \multicolumn{7}{|l|}{ World Bank income level } \\
\hline Low & 21 & 0.24 & $(0.17-0.48)$ & 17 & 0.11 & $(0.00-0.48)$ \\
\hline Lower-middle & 35 & 1.58 & $(0.88-5.67)$ & 36 & 0.57 & $(0.21-1.60)$ \\
\hline Upper-middle & 40 & 10.81 & $(5.08-17.03)$ & 37 & 1.19 & $(0.77-2.60)$ \\
\hline High & 56 & 23.15 & $(16.68-30.91)$ & 54 & 3.83 & $(1.81-7.30)$ \\
\hline
\end{tabular}

Density of nephrologists and nephrology trainees calculated by taking the total number of nephrologists or nephrology trainees provided by each country and dividing it by each country's population, grouped by ISN region and World Bank income group.

${ }^{*}$ Although the median number is 0 for this region, the average number of nephrology trainees is $2.8 \mathrm{pmp}$.

ISN, International Society of Nephrology; NIS, Newly Independent States.

Oceania and Southeast Asia (1.1 pmp), Africa (0.4 pmp), South Asia (0.3 pmp) and North America (2.8 pmp).

\section{Survey response rate and primary responsibility for kidney failure care}

Among the 182 countries invited to participate in the 2018 survey, representatives responded from 160 (88\%) countries (online supplemental table S1). The data revealed significant variations across countries and regions in healthcare worker distribution, responsibilities and shortages (tables 2 and 3). Nephrologists were primarily responsible for providing care to patients with kidney failure in $92 \%$ of countries. Primary healthcare providers and nurse practitioners or nurses with specialised training were responsible for kidney failure care in $22 \%$ and $15 \%$ of countries, respectively. Multidisciplinary teams provided kidney failure healthcare in only $19 \%$ of countries, and health officers and extension workers provided kidney failure care in just $1 \%$ of countries (table 2).

\section{Current capacity of health professionals required for kidney failure care}

In addition to the shortage of nephrologists reported by $70 \%$ of countries surveyed, more than half of countries reported shortages of other healthcare professionals essential for kidney failure care. Relative to other World
Bank income groups, a greater proportion of low-income countries reported shortages of all types of kidney failure healthcare providers (table 3). With regard to nonphysician kidney failure healthcare providers, $71 \%$ of upper-middle-income countries reported a shortage of vascular access coordinators, $20 \%$ reported a shortage of laboratory technicians, and just over half reported shortages of transplant coordinators $(61 \%)$, dialysis nurses $(56 \%)$, dialysis technicians $(54 \%)$, and counsellors and psychologists (54\%) (table 3). Overall, a lower proportion of high-income countries reported shortages in the kidney failure workforce relative to countries in the other World Bank income groups. Although $44 \%$ of highincome countries reported a shortage of dialysis nurses, only $19 \%$ reported a shortage of dialysis technicians. Just over one-third of high-income countries reported shortages of vascular access coordinators $(39 \%)$, and counsellors and psychologists (37\%) (table 3).

\section{DISCUSSION}

Our results confirm initial findings from the baseline survey for the GKHA regarding insufficient workforce capacity to provide kidney care. ${ }^{9}$ There was significant variability in the density of the healthcare workforce for all areas of medicine among countries and income groups, with the highest densities of physicians, nursing 
Table 2 The distribution of clinical responsibility in the delivery of kidney failure care among healthcare providers, $\mathrm{n}(\%)$

\begin{tabular}{|c|c|c|c|c|c|c|c|}
\hline Category & $\mathbf{n}$ & Nephrologists & $\begin{array}{l}\text { Primary } \\
\text { care } \\
\text { physicians }\end{array}$ & $\begin{array}{l}\text { Nurse } \\
\text { practitioners } \\
\text { or specialised } \\
\text { nurses }\end{array}$ & $\begin{array}{l}\text { Multidisciplinary } \\
\text { teams }\end{array}$ & $\begin{array}{l}\text { Health } \\
\text { officers/ } \\
\text { extension } \\
\text { workers }\end{array}$ & Other \\
\hline Overall & 157 & $144(92)$ & $34(22)$ & $23(15)$ & 30 (19) & $2(1)$ & $3(2)$ \\
\hline \multicolumn{8}{|l|}{ ISN region } \\
\hline Africa & 41 & $32(78)$ & $12(29)$ & $4(10)$ & $7(17)$ & $0(0)$ & $1(2)$ \\
\hline $\begin{array}{l}\text { Eastern and Central } \\
\text { Europe }\end{array}$ & 19 & $19(100)$ & $4(21)$ & $0(0)$ & $1(5)$ & $0(0)$ & $0(0)$ \\
\hline $\begin{array}{l}\text { Latin America and the } \\
\text { Caribbean }\end{array}$ & 18 & $18(100)$ & $4(22)$ & $3(17)$ & $5(28)$ & $0(0)$ & $0(0)$ \\
\hline Middle East & 11 & $11(100)$ & $1(9)$ & $4(36)$ & $4(36)$ & $0(0)$ & $0(0)$ \\
\hline NIS and Russia & 9 & $9(100)$ & $2(22)$ & $0(0)$ & $0(0)$ & $1(11)$ & $0(0)$ \\
\hline North America & 9 & $8(89)$ & $2(22)$ & $2(22)$ & $3(33)$ & $0(0)$ & $0(0)$ \\
\hline North and East Asia & 7 & $7(100)$ & $0(0)$ & $3(43)$ & $2(29)$ & $0(0)$ & $0(0)$ \\
\hline $\begin{array}{l}\text { Oceania and Southeast } \\
\text { Asia }\end{array}$ & 15 & $14(93)$ & $5(33)$ & $5(33)$ & 5 (33) & $1(7)$ & $1(7)$ \\
\hline South Asia & 7 & $5(71)$ & $2(29)$ & $0(0)$ & $2(29)$ & $0(0)$ & $1(14)$ \\
\hline Western Europe & 21 & $21(100)$ & $2(10)$ & $2(10)$ & $1(5)$ & $0(0)$ & $0(0)$ \\
\hline \multicolumn{8}{|l|}{ World Bank income level } \\
\hline Low & 22 & $16(73)$ & $9(41)$ & $1(5)$ & $2(9)$ & $0(0)$ & $1(5)$ \\
\hline Lower-middle & 37 & $33(89)$ & $11(30)$ & $4(11)$ & $6(16)$ & $2(5)$ & $1(3)$ \\
\hline Upper-middle & 41 & $39(95)$ & $8(20)$ & $6(15)$ & $11(27)$ & $0(0)$ & $1(2)$ \\
\hline High & 57 & $56(98)$ & $6(11)$ & $12(21)$ & $11(19)$ & $0(0)$ & $0(0)$ \\
\hline
\end{tabular}

Number of countries that reported the healthcare providers primarily responsible for kidney failure clinical care, grouped by ISN region and World Bank income group. Percentages calculated as the number of responding countries divided by the total number of responding countries.

ISN, International Society of Nephrology; n, number of participating countries; NIS, Newly Independent States.

personnel, pharmacists and surgeons in high-income countries, and the lowest densities in low-income countries. The density of nursing personnel was higher than the densities of physicians, surgeons, and pharmacists across countries and income groups. Most of the countries surveyed reported that nephrologists were primarily responsible for delivering kidney failure care. In terms of distribution, the density of nephrologists in high-income countries is over 60 times that in low-income countries, and the majority of low-income countries reported shortages of other key healthcare professionals involved in kidney care. For instance, the availability of pharmacists, surgeons, and nursing personnel is 70-fold, 350-fold and 16-fold higher, respectively, in high-income countries compared with low-income countries. These data highlight the need for strategies to increase the global nephrology workforce, especially in low-income countries.

In kidney failure management, an effective workforce is an essential component of optimal care delivery. ${ }^{19-22}$ Several considerations should be taken into account to accurately interpret data pertaining to the nephrology workforce in diverse global settings. ${ }^{23-26}$ The substantial between-country variation in the organisation of specialised nephrology care is an important factor to be considered when interpreting our findings. For instance, in some countries, nephrologists provide care for the entire spectrum of kidney conditions from early CKD to kidney failure, whereas in other countries, nephrologists only treat patients with established kidney failure and provide more specialised care (ie, dialysis or transplant services). Task shifting, which involves training primary care providers, nurses or other professionals to provide kidney failure care with remote guidance from nephrologists and/or support from standard algorithms, may help improve capacity to deliver high-quality kidney failure care in countries with limited nephrologist availability. ${ }^{2325} 26$

While the densities reported in our survey do not reflect factors such as burden of kidney failure, more nephrologists are needed in low-income countries. A number of factors have been cited as driving shortages in the nephrology workforce across countries and regions with significant variations across countries, ${ }^{21} 27$ including an ageing workforce, declining interest in nephrology among trainees, lack of exposure to nephrology among students and residents, rising costs of medical education and specialist training, inflexible work schedules, erosion of nephrology practice scope by other specialists, 


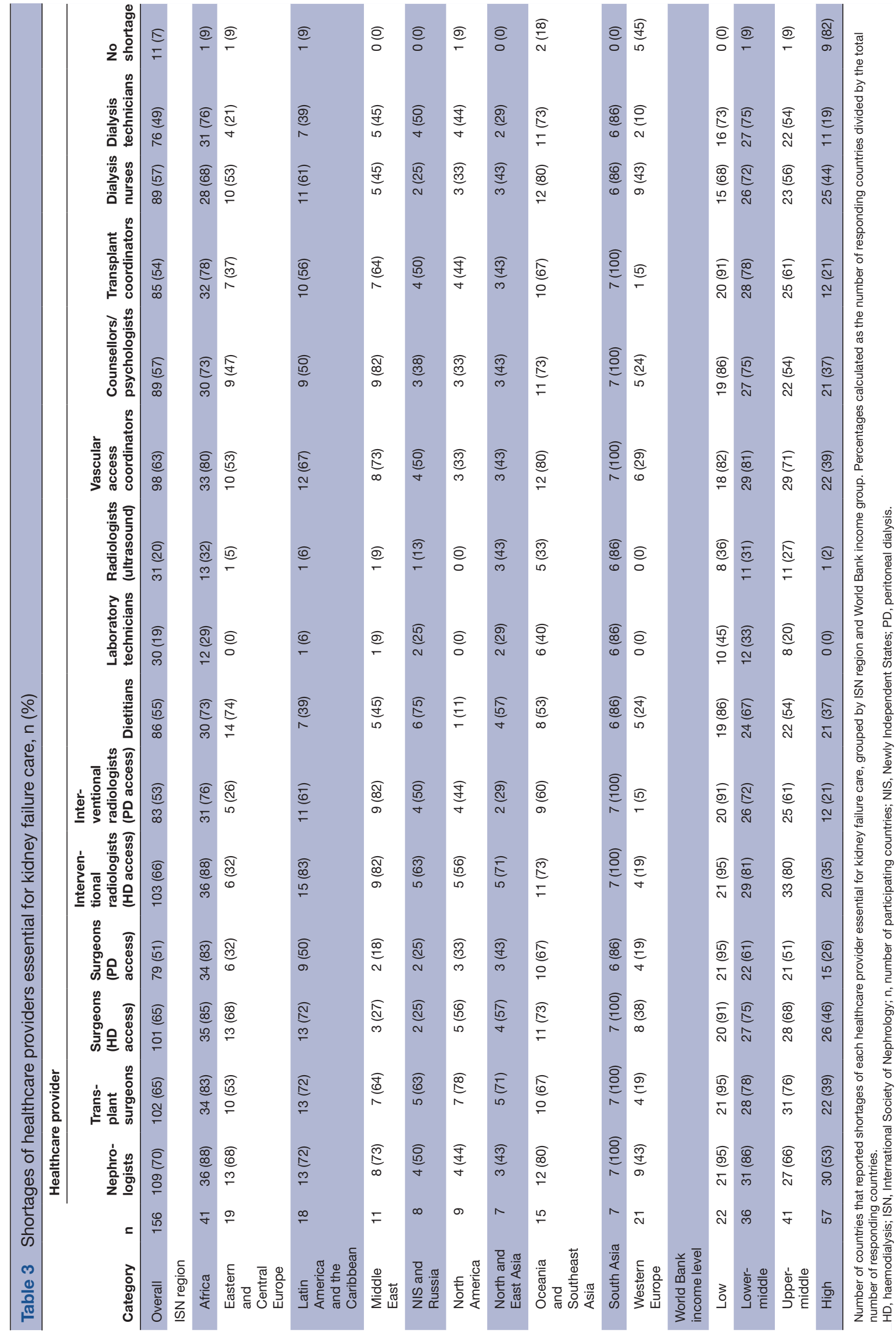

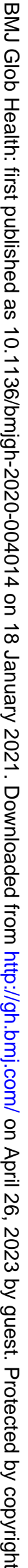


inadequate training, reduced focus on scholarship and academic training, increased demand to meet quality of care standards and the development of new kidney failure care delivery models. ${ }^{27}$

This study provides data regarding the global availability of not only nephrologists and nephrology trainees, but also other healthcare professionals involved in kidney failure care. More than half of countries surveyed reported shortages in nephrologists, interventional radiologists for haemodialysis (HD) access and peritoneal dialysis (PD) access, surgeons for transplantation, HD access and PD access, as well as vascular access and transplant coordinators, counsellors or psychologists, dialysis nurses, and dietitians. Overall, these findings are consistent with data from the Global Burden of Diseases, Injuries and Risk Factors Study 2017, which reported shortages of physicians, nurses or midwives, and pharmacists in almost $50 \%$ of countries in all areas of medicine, not just nephrology. Similar to the findings of our study, the greatest shortages of healthcare workers were reported in sub-Saharan Africa, Southeast Asia, South Asia and Oceania. ${ }^{28}$ Increasing the number of healthcare professionals in these regions and creating multidisciplinary teams are important, considering the complexity of care for patients with kidney failure. Furthermore, distributing the workload for kidney failure care across multiple providers would increase overall care capacity, which is particularly important in areas with significant nephrologist shortages. Another important component of kidney failure care is conservative kidney care, which is widely used as a method of providing non-dialysis medical management for patients with kidney failure. ${ }^{29-31}$ Symptoms, quality of life, psychological, social and family support are essential for comprehensive conservative care. This study demonstrated shortages in counsellors/ psychologists, who are essential healthcare professionals for conservative kidney care. Shortages were greater in low-income and lower-middle-income countries. In countries where kidney replacement therapy was limited or self-funded, conservative kidney care was an important alternative treatment strategy.

Specifically, country-level data regarding the distribution of kidney failure care and professional responsibilities can be used to tailor policies and ensure the effective utilisation of resources to address specific issues. These data can be used to guide workforce development and policy change initiatives across countries and regions. In order to create effective policies to expand local nephrology care, strategies will need to be tailored to each regional healthcare system based on available resources. For instance, in upper-middle-income countries, there are relatively fewer surgeons and interventional radiologists available for PD access compared with the number available for HD access. Resources can be used to increase the availability of physicians who can provide PD access, which may involve training existing HD surgeons and interventional radiologists to perform PD catheter insertions or expanding the scope of other healthcare professionals, such as general physicians and/ or community health officers (particularly in low-income countries), to perform PD catheter insertions. For this to be carried out effectively, nephrology care should be centralised by implementing public health strategies and creating national nephrology agencies to implement public policies and strategies to expand the nephrology workforce. ${ }^{31-34}$

This study provides international agencies, such as the ISN, with data regarding international variability in workforce shortages. Only $41 \%$ of low-income countries had nephrology training programmes. ${ }^{9}$ The ISN sponsors medical trainees from developing countries to pursue fellowship training in nephrology with the goal of increasing the number of trainees and physicians in lower income countries, ${ }^{35}$ in addition to many other initiatives that aim to increase the nephrology workforce in developing countries. ${ }^{36-40}$ However, this study revealed a global shortage of not only nephrologists, but all healthcare professionals involved in kidney care, particularly in low-income countries. Therefore, expanding international initiatives to provide funding to train other healthcare professionals, and facilitating the redistribution of nephrology care to nurses and primary care physicians, may be a more time-effective and cost-effective method of addressing the global nephrology workforce shortage. ${ }^{41} 42$ Healthcare training programmes will need to be modified in order to change professional scopes of practice and develop new competencies. For instance, this may involve nephrologists training to perform kidney ultrasounds, or nurses training to manage outpatient CKD care. This is particularly important in low-income countries, where the overall nephrology workforce is sparse, nephrology training programmes are limited, and the rates of CKD and kidney failure continue to rise. ${ }^{1-39}$ Several strategies have been proposed for lower-middle-income countries regarding expanding their kidney failure workforces. These include: government provision of funding and infrastructure for kidney failure care; forming publicprivate partnerships with industry for kidney failure workforce training; using international nephrology societies to train, fund and expand the kidney failure workforce; creating partnerships with academic medical centres; and using web-based teaching programmes to train physicians, nurses and technicians. ${ }^{43}$ While these strategies are useful, it has to be acknowledged that several competing public values, social and political dynamics as well as resource constraints may influence the achievement of the desired workforce goals for equitable kidney care across countries.

\section{Study limitations}

Our study has some limitations worth noting. First, the lack of standardised frameworks or benchmarks to assess workforce adequacy limits our ability to draw firm conclusions across the diverse settings targeted by our survey. Second, like all questionnaires, our survey introduced the potential for subjectivity (ie, social desirability bias) and 
was highly dependent on respondents' knowledge and perceptions. Although the survey questions were assessed for face validity, there was a baseline presumption that respondents accurately reported the status of the kidney failure workforce in each country. We strove to overcome this limitation by working closely with the ISN's regional boards to select respondents with a range of kidney care expertise to ensure adequate regional representation, and by corroborating findings with regional leaders and secondary data sources.

\section{CONCLUSION}

Overall, nephrologists were primarily responsible for kidney failure care across all regions and countries of the world. Important gaps in workforce capacity exist, particularly in low-income and lower-middle-income countries. Efforts to increase workforce capacity in resource-limited countries are required to ensure high quality of care for patients with kidney failure.

\section{Author affiliations}

${ }^{1}$ Medicine, University of Alberta Faculty of Medicine and Dentistry, Edmonton, Alberta, Canada

${ }^{2}$ Population Health Sciences, University of Bristol, Bristol, UK

${ }^{3}$ Faculty of Medicine and Health Sciences, Stellenbosch University, Cape Town, South Africa

${ }^{4}$ Medicine, Singapore General Hospital, Singapore

${ }^{5}$ George Institute for Global Health, University of New South Wales (UNSW), New Delhi, India

${ }^{6}$ Medicine, University of Alberta, Edmonton, Alberta, Canada

${ }^{7}$ The George Institute for Global Health, Newtown, New South Wales, Australia

${ }^{8}$ Faculty of Science, University of Alberta, Edmonton, Alberta, Canada

${ }^{9}$ Division of Nephrology, University of British Columbia, Vancouver, British Columbia, Canada

${ }^{10}$ Department of Community Health Sciences, University of Calgary, Calgary, Alberta, Canada

${ }^{11}$ Medicine, University of Cape Town, Cape Town, South Africa

${ }^{12}$ School of Medicine, Pontifical Catholic University of Paraná, Curitiba, Brazil

${ }^{13}$ Department of Nephrology and Hypertension, Cleveland Clinic, Glickman Urological and Kidney Institute, Cleveland, Ohio, USA

${ }^{14}$ University of Sydney at Westmead Hospital, Westmead, New South Wales, Australia

${ }^{15}$ Department of Medicine, University of Calgary, Calgary, Alberta, Canada

${ }^{16}$ Department of Nephrology, Metro South and Ipswich Nephrology and

Transplant Services (MINTS), Princess Alexandra Hospital, Brisbane, Queensland, Australia

Twitter Razeen Davids @razeendavids and Vivekanand Jha @vjha126

Acknowledgements The authors thank Kara Stephenson Gehman for carefully editing the English text of the ISN-GKHA and a draft of this manuscript. They also thank Sophanny Tiv for support with the figures and illustrations used in this manuscript.

Contributors $A B$ and DJ had full access to all of the data in the study and take responsibility for the integrity of the data and the accuracy of the data analysis. $A B, A L$ and DJ did the study concept and design. All authors did the acquisition, analysis or interpretation of data. $\mathrm{PR}, \mathrm{AB}$ and $\mathrm{FY}$ drafted the manuscript. All authors made critical revision of the manuscript for important intellectual content. FY did the statistical analysis. $A B, D J$ and $A L$ obtained funding. $A B$ and DJ supervised the study.

Funding This work was supported by the International Society of Nephrology (Grant RES0033080 to the University of Alberta). The ISN provided administrative support for the design and implementation of the study and data collection activities.
Disclaimer The authors were responsible for data management, analysis and interpretation, as well as manuscript preparation, review and approval, and the decision to submit the manuscript for publication.

Competing interests DJ has received consultancy fees, research grants, speaker's honoraria and travel sponsorships from Baxter Healthcare and Fresenius Medical Care; consultancy fees from Astra Zeneca and AWAK; speaker's honoraria and travel sponsorships from ONO; and travel sponsorships from Amgen. He is a current recipient of an Australian National Health and Medical Research Council Practitioner Fellowship. VJ has received grants, speaker honoraria or consultancy fees from GlaxoSmithKline, Biocon, Baxter, Janssen, Medtronic and NephroPlus. He has a policy of all funds being paid to his employer. FC reports grants from NIHR, grants from Kidney Research UK, other from Baxter. HH reports personal fees from AWAK technology, personal fees from Baxter Healthcare, grants from Johnson \& Johnson Company. Other authors have no conflicts of interest to declare.

Patient consent for publication Not required.

Ethics approval The University of Alberta Research Ethics Committee approved this project (protocol number: PR000063121) and all participants provided informed consent.

Provenance and peer review Not commissioned; externally peer reviewed.

Data availability statement Data are available upon request.

Supplemental material This content has been supplied by the author(s). It has not been vetted by BMJ Publishing Group Limited (BMJ) and may not have been peer-reviewed. Any opinions or recommendations discussed are solely those of the author(s) and are not endorsed by BMJ. BMJ disclaims all liability and responsibility arising from any reliance placed on the content. Where the content includes any translated material, BMJ does not warrant the accuracy and reliability of the translations (including but not limited to local regulations, clinical guidelines, terminology, drug names and drug dosages), and is not responsible for any error and/or omissions arising from translation and adaptation or otherwise.

Open access This is an open access article distributed in accordance with the Creative Commons Attribution Non Commercial (CC BY-NC 4.0) license, which permits others to distribute, remix, adapt, build upon this work non-commercially, and license their derivative works on different terms, provided the original work is properly cited, appropriate credit is given, any changes made indicated, and the use is non-commercial. See: http://creativecommons.org/licenses/by-nc/4.0/.

\section{ORCID iD}

Ikechi Okpechi http://orcid.org/0000-0002-6545-9715

\section{REFERENCES}

1 Hill NR, Fatoba ST, Oke JL, et al. Global Prevalence of Chronic Kidney Disease - A Systematic Review and Meta-Analysis. PLoS One 2016;11:e0158765.

2 Levey AS, Coresh J. Chronic kidney disease. Lancet 2012;379:165-80.

3 Xie Y, Bowe B, Mokdad AH, et al. Analysis of the Global Burden of Disease study highlights the global, regional, and national trends of chronic kidney disease epidemiology from 1990 to 2016. Kidney Int 2018:94:567-81.

4 Tonelli M, Wiebe N, Manns BJ, et al. Comparison of the complexity of patients seen by different medical subspecialists in a universal health care system. JAMA Netw Open 2018;1:e184852.

5 Couser WG, Remuzzi G, Mendis S, et al. The contribution of chronic kidney disease to the global burden of major noncommunicable diseases. Kidney Int 2011;80:1258-70.

6 Levin A, Tonelli M, Bonventre J, et al. Global kidney health 2017 and beyond: a roadmap for closing gaps in care, research, and policy. Lancet 2017;390:1888-917.

7 World Health Organization. Monitoring the building blocks of health systems: a handbook of indicators and their measurement strategies. Geneva, Switzerland WHO Press; 2010.

8 Thomas B, Matsushita K, Abate KH, et al. Global cardiovascular and renal outcomes of reduced GFR. J Am Soc Nephrol 2017;28:2167-79.

9 Osman MA, Alrukhaimi M, Ashuntantang GE, et al. Global nephrology workforce: gaps and opportunities toward a sustainable kidney care system. Kidney Int Suppl 2018;8:52-63.

10 Parker MG, Ibrahim T, Shaffer R, et al. The future nephrology workforce: will there be one? Clin J Am Soc Nephrol 2011;6:1501-6.

11 Bello AK, Levin A, Tonelli M, et al. Assessment of global kidney health care status. JAMA 2017;317:1864-81. 
12 Mandayam S, Winkelmayer WC. Worldwide preparedness for kidney health care. JAMA 2017;317:1838-9.

13 Bello AK, Johnson DW, Feehally J, et al. Global kidney health atlas (GKHA): design and methods. Kidney Int Suppl 2017;7:145-53.

14 Bello AK, Levin A, Lunney M, et al. Status of care for end stage kidney disease in countries and regions worldwide: international cross sectional survey. BMJ 2019;367:I5873.

15 Central Intelligence Agency. The world Factbook, 2020. Available: https://www.cia.gov/library/publications/the-world-factbook/geos/ $\mathrm{xx} \cdot \mathrm{html}$

16 Nursing and Midwifery Personnel. Global health Observatory data Repository, 2020. Available: https://www.cia.gov/library/publications/ the-world-factbook/geos/xx.html

17 Pharmaceutical Personnel. Global health Observatory data Repository, 2020. Available: https://apps.who.int/gho/data/node. main.HWFGRP_0080?lang=en

18 Surgical Workforce Reported Data By Country. Global health Observatory data Repository, 2020. Available: https://apps.who.int/ gho/data/node.main.HWF9?lang=en

19 Tummalapalli SL, Peralta CA. Preparing the nephrology workforce for the transformation to value-based kidney care: needs assessment for advancing American kidney health. Clin J Am Soc Nephrol 2019;14:1802-4.

20 Qarni B, Osman MA, Levin A, et al. Kidney care in low- and middleincome countries. Clin Nephrol 2020;93:21-30.

21 Weggemans MM, Friesen F, Kluijtmans M, et al. Critical gaps in understanding the clinician-scientist workforce: results of an international expert meeting. Acad Med 2019;94:1448-54.

22 Ulrich BT, Kear TM. The health and safety of nephrology nurses and the environments in which they work: important for nurses, patients, and organizations. Nephrol Nurs J 2018;45:117-68.

23 Lipstein SH, Kellermann AL. Workforce for 21 st-century health and health care. JAMA 2016;316:1665-6.

24 Association of American Medical Colleges. The complexities of physician supply and demand: projections from 2014 to 2025, 2017. Available: https://aamc-black.global.ssl.fastly.net/production/media/ filer_public/a5/c3/a5c3d565-14ec-48fb-974b-99fafaeecb00/aamc_ projections_update_2017.pdf

25 Tulenko K, Gaye PA, Middleberg MI. Increasing the global health workforce. JAMA 2011;305:998.

26 Gupta R, Bush BP, Dorsey J, et al. Improving the global health workforce crisis: an evaluation of global health Corps. The Lancet Global Health 2015;3:e679.

27 Sharif MU, Elsayed ME, Stack AG. The global nephrology workforce: emerging threats and potential solutions! Clin Kidney J 2016;9:11-22.

28 Lozano R, Fullman N, Abate D, et al. Measuring progress from 1990 to 2017 and projecting attainment to 2030 of the health-related sustainable development goals for 195 countries and territories: a systematic analysis for the global burden of disease study 2017. Lancet 2018;392:2091-138.

29 Murtagh FEM, Burns A, Moranne O, et al. Supportive care: comprehensive conservative care in end-stage kidney disease. Clin J Am Soc Nephrol 2016;11:1909-14.

30 The Australian Institute of Health and Welfare. End stage kidney disease in Australia: total incidence, 2003-2007. Final report. catalogue No. PHE 143. Canberra, New South Wales, Australia Australian Institute of Health and Welfare; 2011.

31 Hemmelgarn BR, James MT, Manns BJ, et al. Rates of treated and untreated kidney failure in older vs younger adults. JAMA 2012;307:2507-15

32 British Renal Society. Multi-Professional renal workforce plan for adults and children with kidney disease. Available: https:// britishrenal.org/workforce/ [Accessed 20 Sep 2020].

33 Hassen M, Archer E, Pellizzon A, et al. Human resources for nephrology in South Africa: a mixed-methods study. PLoS One 2020;15:e0228890

34 Ramirez SPB, Hsu SI-H, McClellan W. Taking a public health approach to the prevention of end-stage renal disease: the NKF Singapore program. Kidney Int Suppl 2003;63:S61-5.

35 International Society of Nephrology. Fellowship program. Available: https://www.theisn.org/images/ISN_Programs/ISN_Fellowship_ Program_Booklet.pdf [Accessed 10 Jan 2020].

36 International Society of Nephrology. ISN-TTS sister transplant centers program. Available: http://stc.theisn.org/ [Accessed 27 Jun 2020].

37 International Society of Nephrology. ISN sister renal centers program. Available: http://src.theisn.org/ [Accessed 27 Jun 2020].

38 International Society of Nephrology. ISN Academy. Available: https:// www.theisn.org/education-external/isn-academy [Accessed 27 Jun 2020].

39 International Society of Nephrology. ISN regional training centers. Available: https://www.theisn.org/news/itemlist/category/97-isnregional-training-centers [Accessed 27 Jun 2020].

40 International Society of Nephrology. ISN educational Ambassadors. Available: http://ea.theisn.org/ [Accessed 27 Jun 2020].

41 Bennett PN, Walker RC, Trask M, et al. The International Society of Nephrology Nurse Working Group: engaging nephrology nurses globally. Kidney Int Rep 2019;4:3-7.

42 Fulton BD, Scheffler RM, Sparkes SP, et al. Health workforce skil mix and task shifting in low income countries: a review of recent evidence. Hum Resour Health 2011;9:1.

43 Swanepoel CR, McCulloch MI, Abraham G, et al. Challenges for sustainable end-stage kidney disease care in low-middleincome countries: the problem of the workforce. Kidney Int Suppl 2020;10:e49-54. 